\title{
Design and Analysis of Electro thermally Actuated Microgripper
}

\author{
Ruchika Vij ${ }^{1}$, Balwinder Singh ${ }^{2}$, D. K. Jain ${ }^{3}$ \\ ${ }^{I}$ Academic and Consultancy Services Division, Centre for development of advanced computing, \\ Mohali, India, 160071
}

\begin{abstract}
Micro-Electro-Mechanical Systems (MEMS) technology offers the opportunity to produce mechanical, electromechanical, and electrochemical devices with the same unprecedented levels of miniaturization, and functionality as modern Very Large Scale Integrated (VLSI). Micro grippers are used for manipulation of biological samples, for assembling of micro parts and for micro assembly. Electro thermal micro grippers are promising tools enabling assembly and manipulation of nano-scale structures. In this paper MEMS based U-shaped thermally actuated micro-gripper is designed using two hot and one cold arm type thermal actuator. Then the effect of coefficient of thermal expansion and poisson's ratio on stress for thermally actuated micro-gripper is analyzed and the results shows that the stress increases with the increase in coefficient of thermal expansion and the stress decreases with the increase in poisson's ratio.
\end{abstract}

Keywords:MEMS, Thermally Actuated Micro-gripper, Coefficient of Thermal Expansion, Poisson's Ratio

\section{Introduction}

MEMS are the emerging field of areas like biotechnology, electronics, mechanical, automotive industries, RF MEMS and communication. MEMS is a process technology which combines the mechanical and electrical components to create tiny integrated systems or devices ranging in size from few micrometers to millimeters. The MEMS based micro-grippers are miniaturized tools specifically designed for handling objects ranging from nanometers up to $400 \mu \mathrm{m}$ in width/diameter. The application areas of the micro-grippers are highprecision pick-and-place operations, micro assembly, nanoassembly, micro-object sorting, force-controlled handling of sensitive objects, bio-research. There are other actuators present like piezoelectric, electrostatic, micro-pneumatic, electromagnetic and shape memory alloy, which can be used to design and manufacture the micro-gripper. But here the thermal actuator is used to design the micro-gripper because of the advantages like large displacement, high accuracy, good repeatability, provides easily controlled micro-actuation, simple in operation, easy to design and fabricate, provide large forces. The basic principle of working of the thermally actuated micro-gripper described in section 1.1, is joule heating (a material crossed by an electrical current, as a result of collision between the floating electrons and the atoms making the material, will get some thermal energy) and thermal expansion (due to heat, the atoms and electrons making the material start vibrating. As the vibration of atom increases, the temperature increases and the atom will excite atoms around it. The atoms will push each other away to get enough space, as their vibration amplitude is large, resulting in increasing the dimensions). In section 1.2, the related work of different authors is discussed. In section 2, the theoretical analysis is done to observe the effect of coefficient of thermal expansion and Poisson's ratio on stress for thermally actuated micro-gripper. In section 3 , the design of the electro thermally actuated micro-gripper using two hot and one cold arm type thermal actuator is discussed. After discussing the results in section 4, the conclusion is discussed in section 5 .

\subsection{Electrothermally Actuated Microgripper}

Micro gripper is made up of two micro actuators having hot arm and cold arm. The basic principle of operation is joule heating and thermal expansion. The actuator consists of two hot (narrow) arms, one cold (wide) arm and the flexure. When $5 \mathrm{~V}$ voltage is applied to the two middle narrower arms, wider arms are floating and other two arms are grounded then the narrower arms gets more heated due to large resistance according to the equation; $\mathrm{R}=\frac{\rho \mathrm{L}}{\mathrm{A}}$ andH $=\mathrm{I}^{2} \mathrm{R}$, where $\mathrm{L}$ is the length, $\mathrm{R}$ is the resistance, and $\mathrm{A}$ is the area of cross section of the arm, $\mathrm{H}$ is the Joule heat produced in the arm and I is the current flowing through the arm. As a result of more heated narrower arms, they will deflect more than wider arms. Thus, the narrower arms create mechanical force and push the structure in direction narrower to wider arm. Also, when the voltage is applied to the two wider arms, two middle narrower arms are grounded and the other two narrower arms are floating, then the structure bends in opposite direction. 


\subsection{Related Work}

Kalaiarasi and HosiminThilagar, (2011) has studied the ETC (Electro Thermal Compliant) devices for different geometry. The modifications are done to improve the displacement of the actuator [1]. Sardan et.al, (2008) has designed the electro thermal microgripper and the temperature distribution, stiffness and end-effector displacement has been modeled [3]. Chronis et.al, (2004) has developed a polymer MEMS-based electro thermal SU-8 microgripper which can be used, with minimal undesired interactions, for the manipulation of the single cells or other biological species [6]. Kaur and Dhariwala, (2012) has studied the effect of actuation parameters on the output of the electro thermal microtweezer [2]. Chronis et.al, (2005) has proposed a design of SU-8 based elcectrothermally actuated microgripper to fill the gap in physiological liquids of the microgrippers which are capable to manipulate biological samples. The proposed microgripper can work in any type of biological assay and is compatible with the liquid operation [7]. Mølhave et.al, (2005) has designed an electrothermally actuated microgripper which can provide a piezoresistive read-out of the gripper deflection [10]. Mayyas et.al, (2007) has discussed the design, fabrication, packaging tradeoffs along with the trade off in the use of electro thermal MEMS devices for the microassembly applications. The several electro thermal endeffectors have been fabricated also discussed the dynamic performance and the practical challenges with the end-effectors [11].

\section{Theoretical Analysis}

To analyze the effect of coefficient of thermal expansion on the stress of the thermally actuated microgripper, the following calculations have been done. Thermal expansion in the micro-gripper due to heat is given [1] in (1):

$$
\Delta \mathrm{L}=\alpha \mathrm{L} \Delta \mathrm{T}
$$

' $\Delta \mathrm{L}$ ' is the thermal expansion, ' $\alpha$ ' is the coefficient of thermal expansion, ' $\Delta T$ ' is the difference in hot and cold arm and ' $\mathrm{L}$ ' is the original length.

The strain produced due to thermal expansion is given in (2):

$$
\varepsilon=\frac{\Delta \mathrm{L}}{\mathrm{L}}
$$

' $E$ ' is the strain , ' $\Delta \mathrm{L}$ ' is the thermal expansion and ' $\mathrm{L}$ ' is the original length.

From (1) and (2), the value of strain is given in (3):

$$
\varepsilon=\alpha \Delta \mathrm{T}
$$

Now, the elastic modulus (young's modulus) is given in (4):

$$
E=\frac{f}{\varepsilon}
$$

Where ' $E$ ' is the elastic modulus (young's modulus), ' $\mathrm{f}$ ' is the stress due to thermal expansion and ' $\varepsilon$ ' is the strain due to thermal expansion.

From (4), the value of stress is given in (5):

$$
f=\varepsilon E
$$

Now put the value of strain $(\varepsilon)$ from (3), the thermal stress comes out is given in (6):

$$
\mathrm{f}=\alpha \mathrm{E} \Delta \mathrm{T}
$$

Where ' $\mathrm{f}$ ' is thermal stress, ' $\mathrm{E}$ ' is the young's modulus (elastic modulus), ' $\alpha$ ' is the coefficient of thermal expansion, ' $\Delta \mathrm{T}$ ' is the temperature difference between hot and cold arm. The actuation for the microgripper is given in (7):

$$
A=\frac{\alpha \mathrm{L}^{2} \Delta \mathrm{T}}{4 \mathrm{w}}
$$

From (7), the value of $\Delta \mathrm{T}$ is given in (8):

$$
\Delta \mathrm{T}=\frac{4 \mathrm{Aw}}{\alpha \mathrm{L}^{2}}
$$

Also the actuation in terms of current is given in (9):

The value of current is given in (10):

$$
\mathrm{A}=\frac{\alpha \mathrm{L}^{2} \mathrm{I}^{2}}{64 \mathrm{kw}^{2} \mathrm{~h}}
$$

$$
\mathrm{I}^{2}=\frac{32 \mathrm{kwh} \mathrm{T}}{9 \rho}
$$

From (8), (9) and (10), the value of ' $\Delta \mathrm{T}$ ' comes out is given in (11):

$$
\Delta \mathrm{T}=\frac{2 \mathrm{~T}^{\prime}}{9}
$$

From (6) and (11), the value of stress is given in (12):

$$
\mathrm{f}=\frac{2 \alpha \mathrm{ET}^{\prime}}{9}
$$

Now, to analyse the effect of Poisson's ratio on stress of the thermally actuated micro-gripper, the following calculations have been done. Poisson's ratio is given in (13):

$$
v=\frac{0.5-\mathrm{E}}{6 \mathrm{k}}(13)
$$


Where ' $v$ ' is the Poisson's ratio, ' $E$ ' is the young's modulus and ' $k$ ' is the bulk modulus.

From (12), the value of ' $E$ ' (young's modulus) comes out is given in (14):

$$
\mathrm{E}=6 \mathrm{k}(0.5-\mathrm{v})(14)
$$

Now put the value of 'E' (young's modulus) from (14) into (12), and then the value of stress comes out is given in (15):

$$
\mathrm{f}=\frac{12 \alpha \mathrm{k}(0.5-v) \mathrm{T}^{\prime}}{9}
$$

Where ' $\mathrm{f}$ ' is the stress for the micro-gripper, ' $\mathrm{k}$ ' is the bulk modulus, ' $\alpha$ ' is the coefficient of thermal expansion and ' $\mathrm{T}$ ' ' is the maximum temperature of the microgripper.

These equations are modeled into the MATLAB and the results for stress are obtained for polysilicon, nickel and platinum for different values of coefficient of thermal expansion and Poisson's ratio.

\section{Design}

A MEMS based U-beam thermally actuated micro-gripper is designed with the basic dimensions given below in the Table1 and the design of the thermally actuated micro-gripper is as shown in Fig. 1.

Table 1 Dimensions of the thermally actuated micro-gripper

\begin{tabular}{cc}
\hline Parameter & Value (meter) \\
\hline Length of the first hot arm (Lh1) & $330 \mathrm{e}-6$ \\
\hline Length of the cold arm (Lc) & $150 \mathrm{e}-6$ \\
\hline Length of the flexure (Lf) & $40 \mathrm{e}-6$ \\
\hline Length of the second hot arm (Lh2) & $205 \mathrm{e}-6$ \\
\hline Width of flexure (Wf) & $3 \mathrm{e}-6$ \\
\hline Width of the first and second hot arm (Wh1, Wh2) & $3 \mathrm{e}-6$ \\
\hline Length of the gap between the arms (Lg) & $3 \mathrm{e}-6$ \\
\hline Width of the cold arm (Wc) & $15 \mathrm{e}-6$ \\
\hline Initial opening (g) & $15 \mathrm{e}-6$ \\
\hline Thickness & $2 \mathrm{e}-6$ \\
\hline Length of the first, second and third anchor (La1) & $4 \mathrm{e}-6$ \\
\hline Width of the first, second and third anchor (Wa1) & $10 \mathrm{e}-6$ \\
\hline Length of the pad (Lp1) & $10 \mathrm{e}-6$ \\
\hline Width of the first pad (Wp1) & $15 \mathrm{e}-6$ \\
\hline Width of the second and third pad(Wp2, Wp3) & $21 \mathrm{e}-6$ \\
\hline Radius of the circle & $1.5 \mathrm{e}-6$ \\
\hline
\end{tabular}

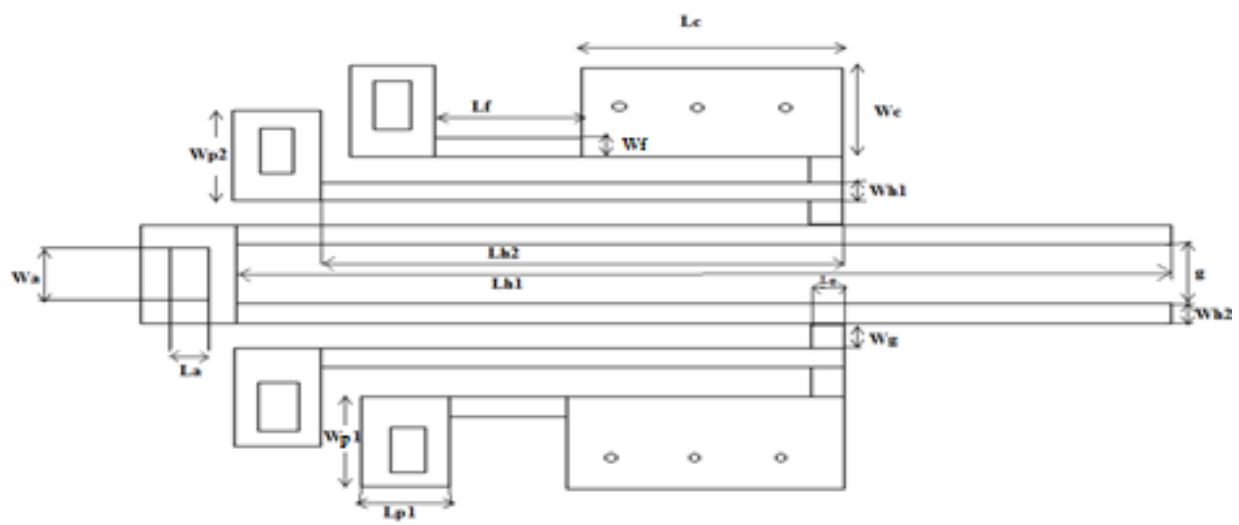

Figure 1: Design of the thermally actuated micro-gripper

The Polysilicon, Nickel and Platinum materials are used one by one for the whole micro-gripper design. The material properties of Polysilicon, Nickel and Platinum are given below in the Table2. 
Table 2 Material Properties

\begin{tabular}{|c|c|c|c|c|}
\hline Sr. No. & Properties & $\begin{array}{l}\text { Value (for } \\
\text { Polysilicon) } \\
\end{array}$ & Value (for Nickel) & $\begin{array}{l}\text { Value (for } \\
\text { Platinum) }\end{array}$ \\
\hline 1. & $\begin{array}{l}\text { Electrical conductivity } \\
\text { (sigma) }\end{array}$ & $5 \mathrm{e} 4$ & $13.8 \mathrm{e} 6[\mathrm{~S} / \mathrm{m}]$ & $8.9 \mathrm{e} 6[\mathrm{~S} / \mathrm{m}]$ \\
\hline 2. & $\begin{array}{l}\text { Coefficient of thermal } \\
\text { expansion (alpha) }\end{array}$ & $2.6 \mathrm{e}-6[1 / \mathrm{K}]$ & $13.4 \mathrm{e}-6[1 / \mathrm{K}]$ & $8.80 \mathrm{e}-6[1 / \mathrm{K}]$ \\
\hline 3. & $\begin{array}{l}\text { Relative permittivity } \\
\text { (epsilonr) }\end{array}$ & 4.5 & 0 & 0 \\
\hline 4. & $\begin{array}{l}\text { Heat capacity at constant } \\
\text { pressure }(\mathrm{Cp})\end{array}$ & $678[\mathrm{~J} /(\mathrm{kg} * \mathrm{~K})]$ & $445\left[\mathrm{~J} /\left(\mathrm{kg}^{*} \mathrm{~K}\right)\right]$ & $133[\mathrm{~J} /(\mathrm{kg} * \mathrm{~K})]$ \\
\hline 5. & Density (rho) & $2320\left[\mathrm{~kg} / \mathrm{m}^{\wedge} 3\right]$ & $8900\left[\mathrm{~kg} / \mathrm{m}^{\wedge} 3\right]$ & $21450\left[\mathrm{~kg} / \mathrm{m}^{\wedge} 3\right]$ \\
\hline 6. & Thermal conductivity $(\mathrm{K})$ & $34[\mathrm{~W} /(\mathrm{m} * \mathrm{~K})]$ & $90.7[\mathrm{~W} /(\mathrm{m} * \mathrm{~K})]$ & $71.6[\mathrm{~W} /(\mathrm{m} * \mathrm{~K})]$ \\
\hline 7. & Young's modulus (E) & $160 \mathrm{e} 9[\mathrm{~Pa}]$ & $219 \mathrm{e} 9[\mathrm{~Pa}]$ & $168 \mathrm{e} 9[\mathrm{~Pa}]$ \\
\hline 8. & Poisson's ratio (nu) & 0.22 & 0.31 & 0.38 \\
\hline 9. & Bulk modulus(k or B) & $97.6[\mathrm{GPa}]$ & --- & --- \\
\hline
\end{tabular}

The physics used for the design of micro-gripper is joule heating and thermal expansion. The boundary conditions to open the micro-gripper are as shown below in Fig. 2.
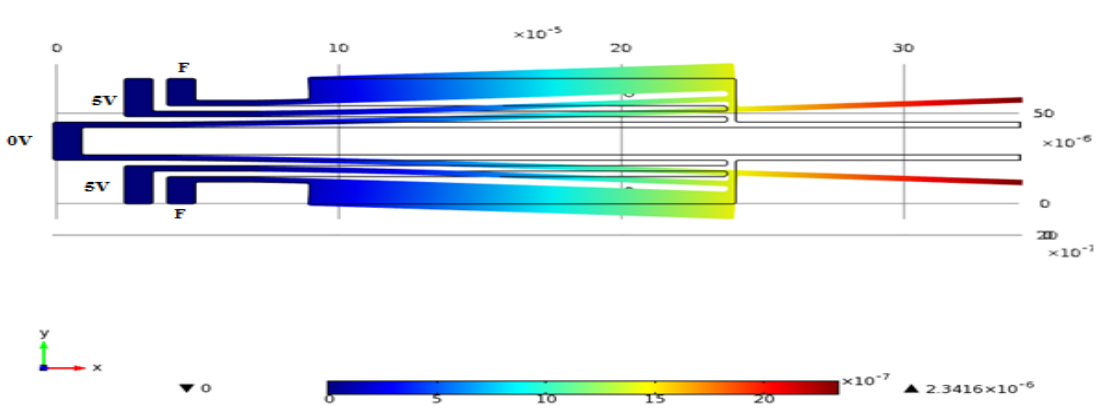

Figure 2: Boundary conditions to open the micro-gripper

The middle two hot arms are grounded, the two cold arms are floating (or not connected) and the other two hot arms are connected with the applied voltage of $5 \mathrm{~V}$. The hot arms are having high resistivity to the current flow as compared to the cold arms resulting that the hot arms (narrower arms) gets more heated than the cold arms (wider arms). The hot arms expand more than cold arms. Finally the structure bends towards the colder arm. Thus the micro-gripper opens up.

\section{Results and Discussion}

The theoretical results obtained from MATLAB and the simulated results obtained from COMSOL Multiphysics software are in close approximation with each other. From the analysis, it has been observed that the stress of the thermally actuated micro-gripper increases with the increase in the coefficient of thermal expansion for different materials. The value of stress, of the thermally actuated micro-gripper, decreases with the increase in the value of Poisson's ratio, for polysilicon material.

The Fig. 3, 4 and 5 shows the comparison between simulation and the theoretical analysis for the measured stress with different values of coefficient of thermal expansion for the thermoelectrically actuated micro-gripper made up of materials polysilicon, nickel and platinum, one by one, respectively.

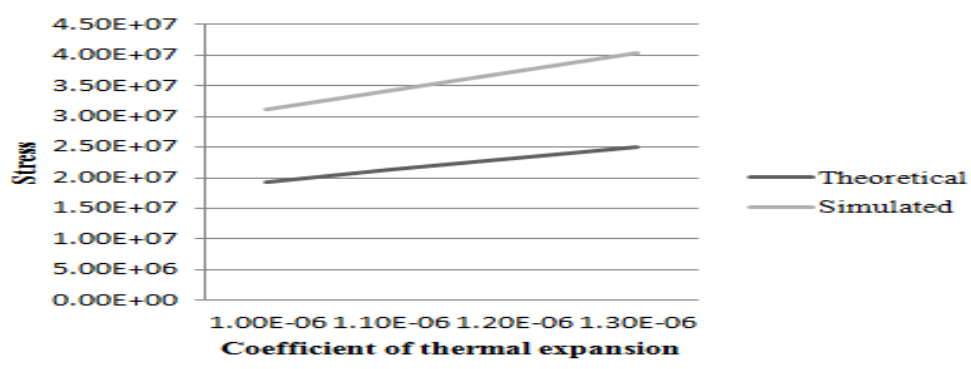

Figure 3: Coefficient of thermal expansion verses stress for micro-gripper made of polysilicon 


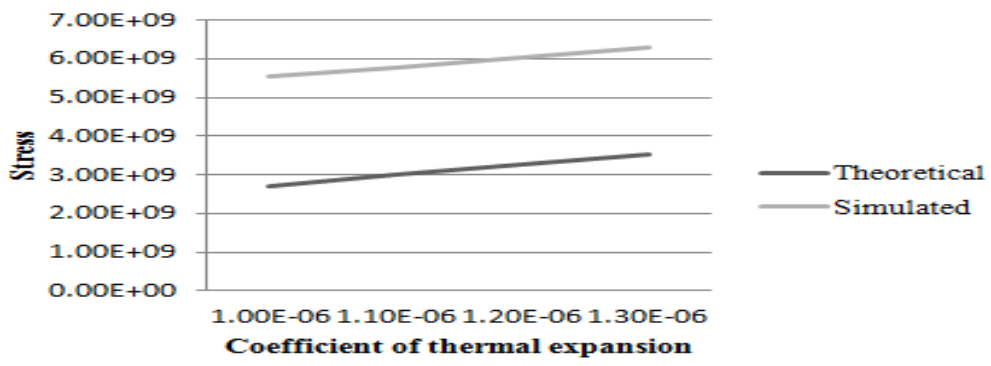

Figure 4: Coefficient of thermal expansion verses stress for micro-gripper made of nickel

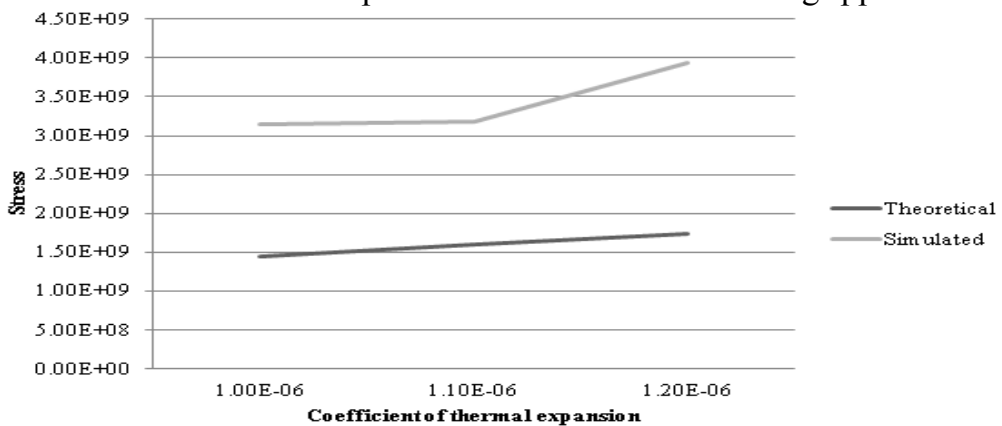

Figure 5: Coefficient of thermal expansion verses stress for micro-gripper made of platinum

The Fig. 6 shows the comparison between simulation and the theoretical analysis for the measured stress with different values of Poisson's ratio for the thermoelectrically actuated micro-gripper made up of polysilicon material.

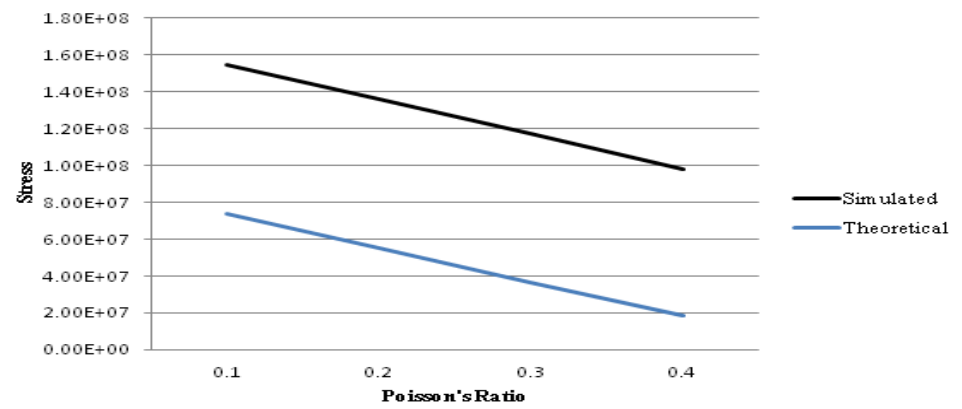

Figure 6: Poisson's Ratio verses stress for micro-gripper made of polysilicon

\section{Conclusion}

The thermally actuated micro-gripper is designed and then the effect of coefficient of thermal expansion and Poisson's ratio is observed on the stress of the micro-gripper using MATLAB and COMSOL Multiphysics software. It has been observed that the stress increases with the increase in coefficient of thermal expansion and the stress decreases with the increase in Poisson's ratio. The effect of coefficient of thermal expansion on stress is analysed for the polysilicon, nickel and platinum materials and the effect of Poisson's ratio on stress is analysed for the polysilicon material. The theoretical and the simulated results are in close approximation with each other.

\section{References}

[1]. A. R. Kalaiarasi and Dr. S. HosiminThilagar, Design and Finite Element Analysis of Electrothermal Compliant Microactuators, Proc. ConfonCOMSOL, Bangalore, 2011.

[2]. ManpreetKaura and SandeepDhariwala, Parameters Affecting Electrothermal Actuation Based Microtweezers, IEEE Journal of Current Engineering and Technology, 2012, 305-309.

[3]. O. Sardan, D. H. Petersen, O. Sigmund and P. Bøggild, Simulation of Topology Optimized ElectrothermalMicrogrippers, Proc. ConfonCOMSOL, Hannover, Germany, 2008.

[4]. Lee, Sang H., Kwang-Cheol Lee, Seung S. Lee, and Hyeon-Seok Oh, Fabrication of an electrothermally actuated electrostatic microgripper, Proc. 12th International Conf. on Tansducers, Solid-State Sensors, Actuators and Microsystems,2003, 552-555.

[5]. Nordström Andersen, Karin, DirchHjorth Petersen, Kenneth Carlson, KristianMølhave, ÖzlemSardanSukas, Andy Horsewell, VolkmarEichhorn, SergejFatikow, and Peter Bøggild, Multimodal electrothermal silicon microgrippers for nanotube manipulation, IEEE Journal of Nanotechnology, 8, 2009, 76-85.

[6]. Chronis, Nikolas, and Luke P. Lee, Polymer MEMS-based microgripper for single cell manipulation,Proc. 17th IEEEConf. on Micro Electro Mechanical Systems (MEMS),2004, 17-20. 
[7]. Chronis, Nikolas, and Luke P. Lee, Electrothermally activated SU-8 microgripper for single cell manipulation in solution, IEEE Journal of Microelectromechanical Systems, 2005, 857-863.

[8]. Patowari, P. K., M. M. Nath, A. S. Bharali, J. Gogoi, and C. K. Singh,Competitive Study of Different Micro-Thermal Actuators for Micro-Electro-Mechanical-System Application, IEEE Journal of Advanced Manufacturing Systems, 1, 2012, 17-26.

[9]. Krecinic, F., T. Chu Duc, G. K. Lau, and P. M. Sarro, Finite element modelling and experimental characterization of an electrothermally actuated silicon-polymer micro gripper, IEEE Journal of Micromechanics and Microengineering, 6, 2008, 1-7.

[10]. Mølhave, Kristian, and Ole Hansen,Electro-thermally actuated microgrippers with integrated force-feedback, IEEE Journal of Micromechanics and Microengineering, 15, 2005, 1265-1270.

[11]. Mayyas, Mohammad, Ping Zhang, Woo Ho Lee, PanosShiakolas, and Dan Popa, Design tradeoffs for electrothermalmicrogrippers, Proc. IEEE Conf. on InternationalRobotics and Automation, 2007, 907-912.

[12]. Kim, K., Liu, X., Zhang, Y., \& Sun, Y., Micronewton force-controlled manipulation of biomaterials using a monolithic MEMS microgripper with two-axis force feedback, Proc. IEEE Conf. on International Robotics and Automation (ICRA), 2008, 31003105.

[13]. Piriyanont, Busara, and S. O. Moheimani, Design, modeling, and characterization of a MEMS micro-gripper with an integrated electrothermal force sensor, Proc.IEEE/ASME Conf. on International Advanced Intelligent Mechatronics (AIM),2013, 348-353. 